\title{
Strain-Induced Precipitation Kinetics of Vanadium Carbonitride Precipitates with the Cubic Structure in High-Strength Weathering Steels
}

\author{
J. Cheng, J. Qing, and H. F. Shen ${ }^{1}$
}

Key Laboratory for Advanced Materials Processing Technology, Ministry of Education, School of Materials Science and Engineering, Tsinghua University, Beijing, China

${ }^{1}$ shen@tsinghua.edu.cn

The strain-induced precipitation kinetic model of vanadium carbonitride $[V(C, N)]$ precipitates with the cubic structure in vanadium-nitrogen $(V-N)$ microalloyed high-strength weathering steels was constructed and validated. The $V(C, N)$ precipitates possess an fcc structure with the lattice sites and octahedral interstitial sites (O-sites) being occupied with $V$ atoms, and $C$ and $N$ atoms, respectively. The model is based on the cubic structure for $V(C, N)$ precipitates instead of the spherical one, since recent experimental results clearly demonstrate that the strain-induced precipitation of $V(C, N)$ in austenite is of the cubic structure. The nitrogen content effect on precipitation-temperature-time (PTT) curve pattwerns was also studied. With the nitrogen content, the PTT curve nose temperature increased, and the curves shifted left. When the nitrogen content in steels was dropped, PTT curves of $V(C, N)$ precipitates in austenite acquired an $S$-shape, since free energy conversion is nonlinear. Additionally, thermodynamic software was employed to calculate the phase equilibrium of $V(C, N)$ precipitates in the new high-strength weathering steels. The $N$ site fraction of $N$ during the $V(C, N)$ precipitation was much larger for steels with high $N$ contents, compared to those with low ones.

Keywords: strain-induced precipitation, kinetic model, cubic $\mathrm{V}(\mathrm{C}, \mathrm{N})$ precipitates, microalloyed steel, austenite, precipitation-temperature-time curve, thermodynamic calculation.

Introduction. With the development of high-speed and heavy-load railways, high strength and good corrosion resistance are required for the new generation of weathering steels. An effective method of improvinh the strength of weathering steel is microalloying. The addition of trace alloying elements of $\mathrm{Nb}, \mathrm{V}$, and $\mathrm{Ti}$ in weathering steel has a strong effect on the microstructure and physical properties [1]. The microalloying refines grains and provides the precipitation strengthening [2], which makes the precipitation of microalloying carbides and nitrides in high-strength weathering steels very topical.

Many studies concerning strain-induced precipitation kinetic models of microalloying elements in austenite phases were conducted. Thus, the model for prediction of the precipitation start time of $\mathrm{Nb}(\mathrm{C}, \mathrm{N})$ proposed by Dutta and Sellars [3] was based on the classical theory of nucleation and an extensive analysis of experimental results. A similar model on Ti microalloyed steels was proposed by Liu and Jonas [4], while a detailed model for $\mathrm{Nb}$ microalloyed steels with the heterogeneous nucleation of precipitates on dislocations was introduced by Liu [5]. A comprehensive model of the precipitation kinetics considering the nucleation, growth, and coarsening of precipitates in $\mathrm{Nb}$ microalloyed steels was adopted by Dutta et al. [6]. A computational model for vanadium carbonitride [V(C, N)] precipitation kinetics proposed by Maugis and Gouné [7] considered the diffusion effect of nitrogen, carbon, and niobium on precipitates during their nucleation. The precipitation kinetics model for vanadium (V) microalloyed steel was also studied by Fang and Yong [8] and Yong [9], which considered the heterogeneous nucleation of spherical $\mathrm{V}(\mathrm{C}, \mathrm{N})$ precipitates on dislocations. The precipitation-temperature-time (PTT) curve and nucleation rate temperature (NrT) curve of the second phase were calculated. The model was used to predict the temperature for the fastest precipitate nucleation. The model for the straininduced precipitation kinetics of $\mathrm{V}(\mathrm{C}, \mathrm{N})$ during hot-working of precipitation-hardened 
ferritic-pearlitic steels was studied by Mukherjee et al. [10]. They considered the heterogeneous nucleation of precipitates on dislocation nodes and predicted the volume fraction, size, and composition of precipitates. The precipitation of $\mathrm{V}(\mathrm{C}, \mathrm{N})$, as the second phase particle, is vital for vanadium-nitrogen $(\mathrm{V}-\mathrm{N})$ microalloyed high-strength weathering steels. The aim of this study is to take into account that the precipitation of the second phase depends on the type of nucleation, growth, and diffusion transformation. Given this, a new model for the strain-induced precipitation kinetics of cubic $\mathrm{V}(\mathrm{C}, \mathrm{N})$ precipitates is constructed based on the Johnson-Mehl-Avrami equation. It makes use of the Adrian model to calculate the equilibrium phase information and the L-J model to calculate the free volume of precipitates. The effect of nitrogen content on PTT curves is also studied, and thermodynamic calculations on $\mathrm{V}(\mathrm{C}, \mathrm{N})$ precipitation in $\mathrm{V}-\mathrm{N}$ microalloyed high-strength weathering steels are peformed.

1. Model of Strain-Induced Precipitation Kinetics of Cubic V(C, N) Precipitates. Deformation is known to enhance the precipitation kinetics of $\mathrm{V}(\mathrm{C}, \mathrm{N})$ precipitates, as it introduces dislocations into the matrix. These dislocations then act as heterogeneous nucleation sites for precipitates. This process is energetically favorable if the precipitate particles can reduce the energy of the dislocation lines. Hence, dislocation nodes in the three-dimensional network of dislocations and subgrain boundaries in a deformed matrix should act as preferred nucleation sites for precipitates. The above models adopted spherical geometries of the precipitates. However, the experimental results of Zajac [11] clearly demonstrated that the strain-induced precipitation of $\mathrm{V}(\mathrm{C}, \mathrm{N})$ in austenite is cubic. Therefore the strain-induced precipitation of cubic $\mathrm{V}(\mathrm{C}, \mathrm{N})$ precipitates on the dislocation lines has been incorporated in the present model. The schematic representation of the cubic precipitate structure is shown in Fig. 1.

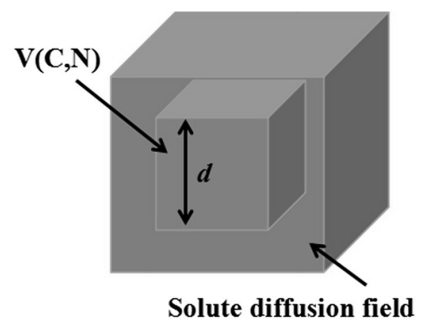

Fig. 1. Schematic representation of the cubic precipitate structure ( $d$ is the length of cubic precipitates).

1.1. Thermodynamics. In V-N microalloyed high-strength weathering steels, carbide and nitride formed with the $\mathrm{V}$ element are interstitial phases filling the $f c c$ metallic lattice of $\mathrm{NaCl}$ type. Similar crystal structures of carbides and nitrides make them mutually soluble. For simplicity, the chemical formula of the carbonitride is assumed to be $\mathrm{VC}_{y} \mathrm{~N}_{1-y}$ or $\mathrm{VC}_{x} \mathrm{~N}_{1-x}$, where $y$ is the site fraction of molar mass, and $x$ is the site fraction of mass weight. The thermodynamic model is based on the Adrian model [2] and the conservation of mass.

Thus, the equilibrium in $\mathrm{V}-\mathrm{N}$ microalloyed high-strength weathering steels is described by the following equations:

$$
\begin{gathered}
\ln \frac{y K_{V C}}{\left[V_{0}\right]\left[C_{0}\right]}+(1-y)^{2} \frac{L_{C N}}{R T}=0, \\
\ln \frac{(1-y) K_{V N}}{\left[V_{0}\right]\left[N_{0}\right]}+y^{2} \frac{L_{C N}}{R T}=0,
\end{gathered}
$$




$$
\begin{gathered}
V_{0}=\frac{1}{2} f+(1-f)\left[V_{0}\right], \\
C_{0}=\frac{y}{2} f+(1-f)\left[C_{0}\right], \\
N_{0}=\frac{1-y}{2} f+(1-f)\left[N_{0}\right], \\
\frac{C_{0}-\left[C_{0}\right]}{V_{0}-\left[V_{0}\right]}=\frac{y A_{C}}{A_{V}}, \\
\frac{N_{0}-\left[N_{0}\right]}{V_{0}-\left[V_{0}\right]}=\frac{(1-y) A_{N}}{A_{V}},
\end{gathered}
$$

where $\left[V_{0}\right],\left[C_{0}\right]$, and $\left[N_{0}\right]$ refer to the solubility of the corresponding components at a given temperature, $V_{0}, C_{0}$, and $N_{0}$ are the nominal contents of the corresponding components, $y$ is the proportion of the corresponding components in the precipitate phase, $R$ is the ideal gas constant, and $f$ is the molar fraction of the carbonitride. If the subscript is 0 , these data are atomic fractions. $K_{V X}$ is given by Eq. (8):

$$
K_{V X}=\left[V_{0}\right]\left[X_{0}\right]=\frac{A_{F e}^{2}}{10^{4} A_{V} A_{X}} \times 10^{B-A / T},
$$

where $A_{F e}, A_{V}$, and $A_{X}$ are the related atomic masses of the respective elements, $X$ is the element $\mathrm{C}$ or $\mathrm{N}$, and $M$ is the element $\mathrm{V}, \mathrm{C}$, or $\mathrm{N}$. To convert the concentration of an element $(M \%)$ into atomic fractions, the following equation is used:

$$
M_{0}=\frac{M \% A_{F e}}{100 A_{M}} .
$$

1.2. Nucleation. The energies associated with the process of nucleation for precipitates on dislocation nodes are very complex. However, in order to incorporate this phenomenon in the present calculations, it is assumed that the nucleation of precipitates in dislocation nodes leads to the elimination of the core energy of the dislocation over the length of the nucleating particle. Hence, neglecting the strain energy term, the Gibbs energy for the heterogeneous nucleation of cubic $\mathrm{V}(\mathrm{C}, \mathrm{N})$ precipitates is given by

$$
\Delta G=\Delta G_{\text {chem }}+\Delta G_{\text {int }}+\Delta G_{\text {dist }}
$$

where $\Delta G_{\text {chem }}$ is the chemical free energy, $\Delta G_{i n t}$ is the interfacial energy, and $\Delta G_{\text {dist }}$ is the dislocation core energy.

Assuming a cubic nucleus length $d$, the chemical free energy change expressed as $\Delta G_{\text {chem }}$ in Eq. (10) is given by

$$
\Delta G_{\text {chem }}=d^{3} \Delta G_{V}
$$

where $\Delta G_{V}$ is the driving force for the nucleation. 
The interfacial energy $\Delta G_{i n t}$ in Eq. (10) is given by

$$
\Delta G_{\text {int }}=6 d^{2} \gamma
$$

where $\gamma$ is the specific interface energy per unit area of a nucleus of length $d$ between precipitates and matrix.

The dislocation core energy $\Delta G_{\text {dist }}$ in Eq. (10) is given by

$$
\Delta G_{\text {dist }}=-A d,
$$

where

$$
\begin{gathered}
A=G_{\gamma-F e} b^{2} / 4 \pi(1-v), \\
G_{\gamma-F e}=0.5 E_{\gamma-F e} /(1+v) .
\end{gathered}
$$

In Eqs. (14) and (15), $A$ is dislocation energy per unit length of dislocation line, $v$ is Poisson's ratio, $G_{\gamma-F e}$ is the shear modulus in the austenite matrix, $E_{\gamma-F e}$ is the elasticity modulus in the austenite matrix, and $b$ is the Burgers vector.

1.2.1. Driving Force for Nucleation. In this case, the driving force is given by Eq. (16) as in $[4,7,10]$,

$$
\Delta G_{V}=-\frac{R T}{V_{V(C, N)}}\left[\ln \frac{C_{V}^{S S}}{C_{V}^{e}}+y \ln \frac{C_{C}^{S S}}{C_{C}^{e}}+(1-y) \ln \left(\frac{C_{N}^{S S}}{C_{N}^{e}}\right)\right],
$$

where $V_{V(C, N)}$ is the molar volume of V(C,N) precipitates, $C_{V}^{S S}, C_{C}^{S S}$, and $C_{N}^{S S}$ are the solid solution fractions of the corresponding components at the start of the precipitation process during an isothermal precipitation treatment, $C_{V}^{e}, C_{C}^{e}$, and $C_{N}^{e}$ are equilibrium fractions at the interface.

Using Eqs. (1)-(7), the unknown equilibrium compositions in the solid solution in Eq. (16) are replaced by $K_{V C}$ and $K_{V N}$,

$$
\Delta G_{V}=-\frac{R T}{V_{V(C, N)}} \ln \left[\frac{C_{V} C_{C}^{y} C_{N}^{1-y}}{\left(y K_{V C}\right)^{y}\left\{(1-y) K_{V N}\right\}^{1-y}}\right] .
$$

In the above equation, $C_{i}(i=\mathrm{V}, \mathrm{C}, \mathrm{N})$ is the composition of the supersaturated austenite in terms of $\mathrm{V}, \mathrm{C}$, or $\mathrm{N}$ (in atom fractions) and $y$ is the composition of the precipitate, which for the critical nucleus is given by

$$
y=\left[1+\frac{C_{N} K_{V C}}{C_{C} K_{V N}}\right]^{-1}
$$

1.2.2. Critical Length of the Nucleus. The critical length of the nucleus at equilibrium with the matrix $\left(d_{d}^{*}\right)$ is that value of $d$, for which the activation energy, $\Delta G$, given by Eq. (10), reaches a maximum. The critical length of the nucleus $d_{d}^{*}$ is given by

$$
d_{d}^{*}=-\frac{2 \gamma}{\Delta G_{V}}\left[1+\left(1+\beta^{\prime}\right)^{1 / 2}\right]
$$


where

$$
\beta^{\prime}=\frac{A \Delta G_{V}}{12 \gamma^{2}}
$$

In Eqs. (19) and (20), $\beta^{\prime}$ is a parameter related to the shear modulus and interfacial energy.

1.2.3. Energy of the Critical Nucleus. The energy of the critical nucleus, $\Delta G_{d}^{*}$, is given by

$$
\begin{gathered}
\Delta G_{d}^{*}=\left(1+\beta^{\prime}\right)^{3 / 2} \Delta G^{*}, \\
\Delta G^{*}=\frac{32 \gamma^{3}}{\Delta G_{V}^{2}},
\end{gathered}
$$

where $\Delta G_{d}^{*}$ is the energy of the critical nucleus when the nucleation of precipitates is on dislocation nodes and $\Delta G^{*}$ is the homogeneous nucleation energy.

1.2.4. Nucleation Rate. According to the precipitation mechanism of cubic $\mathrm{V}(\mathrm{C}, \mathrm{N})$ precipitates, nucleation sites depend on the density of dislocations in the austenite matrix. With the density of dislocation as $\rho$, the cubic pipe length of a nucleus on a dislocation site as $2 b$, and the volume fraction of dislocations in parent phase as $\left(\rho b^{2}\right)$, the nucleation rate on the dislocation $I_{d}$ can be defined as

$$
I_{d}=\rho b^{2} \frac{d_{d}^{* 2}}{d^{* 2}} \exp \left(\frac{Q-Q_{d}}{k T}\right) \exp \left[\frac{1-\left(1+\beta^{\prime}\right)^{3 / 2} \Delta G^{*}}{k T}\right] I,
$$

where $d^{*}$ is the critical size of a homogeneous nucleus, $Q$ is the volume diffusion activation energy, $Q_{d}$ is the diffusion activation energy, $T$ is temperature (in $\mathrm{K}$ ), and $I$ is the homogeneous nucleation rate.

1.3. Growth. For each particle with the length $d$, the growth rate must be determined as a function of the composition of the solid solution. Based on the mass balance at the precipitate/matrix interface, the classical Zener equation [12] for the growth rate is

$$
\begin{gathered}
\frac{\partial d}{\partial t}=\frac{D_{V}}{d} \frac{C_{0}-C_{M}}{C_{P}-C_{M}}, \\
d^{2}=\frac{2\left(C_{0}-C_{M}\right)}{C_{P}-C_{M}} D_{V} t,
\end{gathered}
$$

where $C_{0}$ is the composition of vanadium in solid solution during an isothermal precipitation treatment, $C_{P}$ and $C_{M}$ are compositions of vanadium at the interface of the $\mathrm{V}(\mathrm{C}, \mathrm{N})$ precipitates and parent phases, respectively, and $D_{V}$ is the diffusion coefficient of vanadium.

1.4. Model for Precipitation Kinetics on Dislocation PTT Curve. The volume fraction of the second phase can be assessed via the Johnson-Mehl-Avrami equation [13-15]. The total equilibrium precipitation amount of the second phase, denoted as $f$, is

$$
f=1-\exp \left(-B t^{n}\right)
$$

where $n$ is the Avrami index and $B$ is related to the nucleation and growth mechanisms. 
Generally, the precipitation start time $(P S)$ and the precipitation finish time $(P f)$ of the PTT curve are defined with 5 and $95 \%$ of precipitation, respectively,

$$
\begin{gathered}
\lg t_{0.05}=-1.28994-\lg C-\lg \frac{15 \tau \rho b^{2} l \lambda^{2}}{8 D_{V}^{1 / 2}\left[\frac{2\left(C_{0}-C_{M}\right)}{C_{P}-C_{M}}\right]^{3 / 2}}- \\
-2 \lg d_{d}^{*}+\frac{1}{\ln 10} \frac{\left(1+\beta^{\prime}\right)^{3 / 2} \Delta G^{*}+\frac{5}{3} Q}{k T} \\
\lg t_{0}=\lg C-\lg \frac{15 \tau \rho b^{2} l \lambda^{2}}{8 D_{V}^{1 / 2}\left[\frac{2\left(C_{0}-C_{M}\right)}{C_{P}-C_{M}}\right]^{3 / 2}}
\end{gathered}
$$

where

$$
\lambda^{2}=\frac{2\left(C_{0}-C_{M}\right)}{C_{P}-C_{M}} .
$$

In Eqs. (27) and (28), $\tau$ is the effective nucleation time and $l$ is the length of the dislocation line.

The respective precipitation start $\left(P_{S}, t_{0.05}\right)$ and finish $\left(P f, t_{0.95}\right)$ times are as follows:

$$
\begin{gathered}
\lg \frac{t_{0.05}}{t_{0}}=-1.28994-2 \lg d_{d}^{*}+\frac{1}{\ln 10} \frac{\left(1+\beta^{\prime}\right)^{3 / 2} \Delta G^{*}+\frac{5}{3} Q}{k T}, \\
\lg \frac{t_{0.95}}{t_{0.05}}=\frac{1}{1.5} \lg \left(\frac{\ln 0.05}{\ln 0.95}\right) .
\end{gathered}
$$

1.5. Input Data. The input data of the strain-induced precipitation kinetics model for cubic $\mathrm{V}(\mathrm{C}, \mathrm{N})$ precipitates in high-strength weathering steels are summarized in Table 1.

\section{Results.}

2.1. Model Verification. Based on the proposed model, the constructed PTT curves for steels (Steel_1 and Steel_2 in Table 2) are plotted in Fig. 2a. As can be seen, in the austenite transition temperature range, the PTT curves of Steel_1 and Steel_2 exhibit the standard C-type shape, which indicates that the precipitation of $\mathrm{V}(\mathrm{C}, \mathrm{N})$ is a diffusion-controlled process. The PTT curves of Steel_1 and Steel_2 in Fig. 2a show obvious nose points, at $\sim 850^{\circ} \mathrm{C}$. According to the experimental data of Fang [16], the temperatures at the nose points in Fig. $2 \mathrm{~b}$ are $\sim 850^{\circ} \mathrm{C}$, which fits the calculated results.

\subsection{Model Application and Analysis.}

2.2.1. PTT Curve of $V(C, N)$ Precipitation in $V-N$ Microalloyed High-Strength Weathering Steel. Based on the proposed model, the calculated results of the PTT curve (for Steel_e in Table 3) are shown in Fig. 3. In the austenite transition temperature range, the PTT curves of Steel_e have a standard C-type shape and obvious nose points at $\sim 875^{\circ} \mathrm{C}$.

2.2.2. Effect of Nitrogen Content on Precipitation of $V(C, N)$. Figure 4 illustrates the nitride content effect on the site fraction of the $\mathrm{C}$ element in precipitation of $\mathrm{V}(\mathrm{C}, \mathrm{N})$ in austenite with various initial compositions (Steel_a, Steel_b, Steel_c, Steel_d, and Steel_e 
T a b 1 e 1

Values [7, 9] of the Input Data for the Calculations

\begin{tabular}{|l|c|c||}
\hline \multicolumn{1}{|c|}{ Characteristic } & Symbol & Value \\
\hline Solubility of VN & $\lg \left(K_{V N}\right)$ & $3.63-8700 / T$ \\
\hline Solubility of VC & $\lg \left(K_{V C}\right)$ & $6.72-9500 / T$ \\
\hline Relative atomic masses of $\mathrm{C}$ & $A_{C}$ & 12.011 \\
\hline Relative atomic masses of $\mathrm{N}$ & $A_{N}$ & 14.0067 \\
\hline Relative atomic masses of $\mathrm{V}$ & $A_{V}$ & 50.9414 \\
\hline Diffusion coefficient of carbon $\left(\mathrm{cm}^{2} / \mathrm{s}\right)$ & $D_{C}$ & $0.1 \exp (-137500 / R T)$ \\
\hline Diffusion coefficient of nitrogen $\left(\mathrm{cm}^{2} / \mathrm{s}\right)$ & $D_{N}$ & $0.91 \exp (-168600 / R T)$ \\
\hline Diffusion coefficient of vanadium $\left(\mathrm{cm}^{2} / \mathrm{s}\right)$ & $D_{V}$ & $0.25 \exp (-264200 / R T)$ \\
\hline Interface energy $\left(\mathrm{J} \cdot \mathrm{m}^{2}\right)$ & $\gamma$ & 0.5 \\
\hline Molar volume of $\mathrm{V}(\mathrm{C}, \mathrm{N})\left(\mathrm{cm} / \mathrm{mol}^{3}\right)$ & $V_{V(C, N)}$ & 10.65 \\
\hline Density of dislocation $\left(\mathrm{m}^{-2}\right)$ & $\rho$ & $10^{14} \cdot \mathrm{m}^{-2}$ \\
\hline Volume diffusion activation energy $(\mathrm{J} / \mathrm{mol})$ & $Q$ & 264000 \\
\hline Poisson's ratio & $v$ & 0.35 \\
\hline Elastic modulus of austenite $(\mathrm{MPa})$ & $E_{\gamma-F e}$ & $254680-114.76 T$ \\
\hline
\end{tabular}

T a b 1 e 2

Chemical Compositions of Steels (wt.\%, the rest is Fe)

\begin{tabular}{|c|c|c|c|c|c||}
\hline Steel & C & Si & Mn & V & N \\
\hline Steel_1 & 0.05 & 0.3 & 1.5 & 0.08 & 0.015 \\
\hline Steel_2 & 0.05 & 0.3 & 1.5 & 0.08 & 0.020 \\
\hline
\end{tabular}

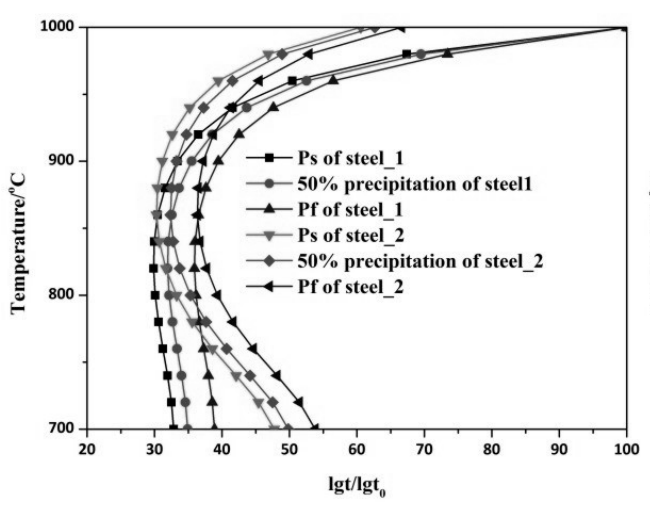

a

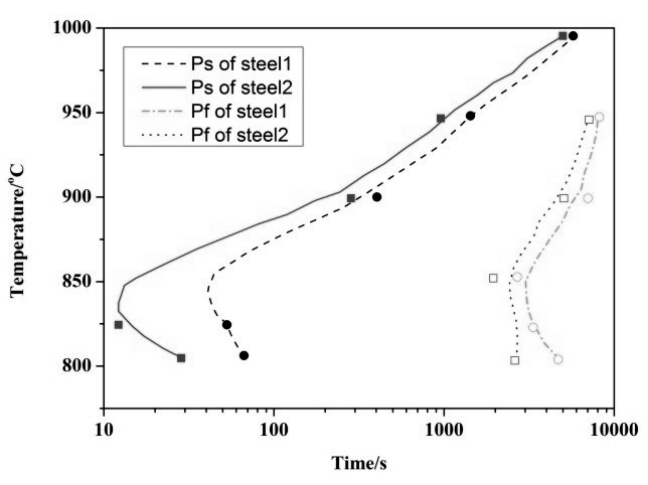

b

Fig. 2. Calculated results of the PTT curve (a) and experimental measurements [16] (b).

in Table 3). As vanadium nitride (VN) has a fairly high equilibrium solid solution concentration in austenite, the nitrogen content has a strong effect on the precipitation of $\mathrm{V}(\mathrm{C}, \mathrm{N})$ in austenite. 
T a b 1 e 3

Chemical Compositions of V-N Microalloyed High-Strength Weathering Steels

\begin{tabular}{||c|c|c|c|c|c|c||}
\hline \multirow{2}{*}{ Steel } & \multicolumn{7}{|c||}{ Weight percent of alloying elements } & $\mathrm{N}$ \\
\cline { 2 - 7 } & Common elements & $\mathrm{C}$ & $\mathrm{Cr}$ & $\mathrm{V}$ & 0.12 & 0.007 \\
\hline Steel_a & $\mathrm{Si}$ & 0.400 & 0.03 & 4.0 & 0.12 & 0.010 \\
\hline Steel_b & $\mathrm{Mn}$ & 0.700 & 0.03 & 4.0 & 0.12 & 0.018 \\
\hline Steel_c & $\mathrm{Ni}$ & 0.250 & 0.03 & 4.0 & 0.12 & 0.024 \\
\hline Steel_d & $\mathrm{Cu}$ & 0.450 & 0.03 & 4.0 & 0.12 & 0.030 \\
\hline Steel_e & $\mathrm{Al}$ & 0.030 & 0.03 & 4.0 & 0.12 & 0.001 \\
\hline Steel_f & $\mathrm{Ti}$ & 0.015 & 0.03 & 4.0 & & \\
\hline \hline
\end{tabular}

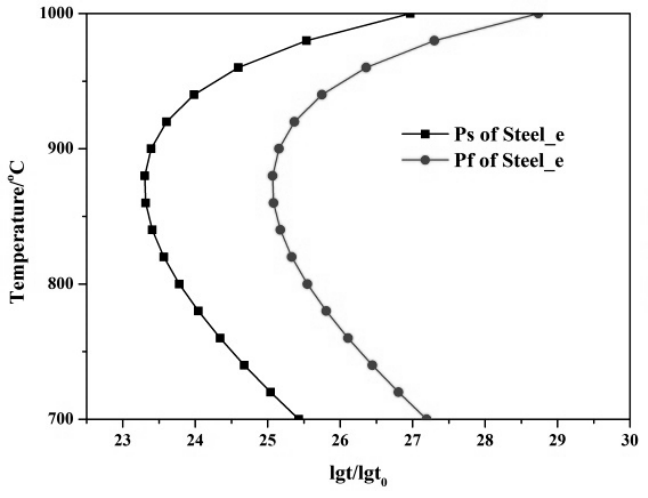

Fig. 3

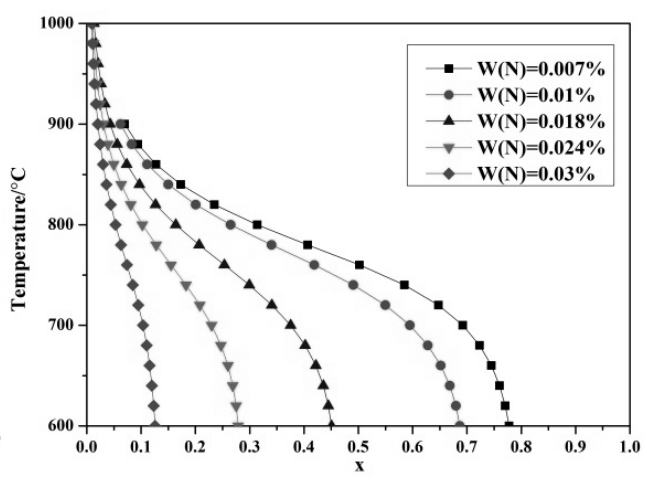

Fig. 4

Fig. 3. PTT curves of vanadium carbonitride precipitation.

Fig. 4. Effect of nitrogen content on the site fraction of the $\mathrm{C}$ element in the precipitation of vanadium carbonitride in austenite.

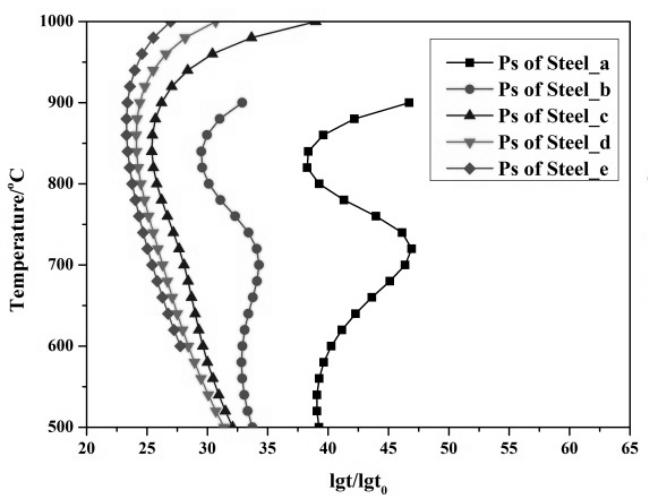

Fig. 5

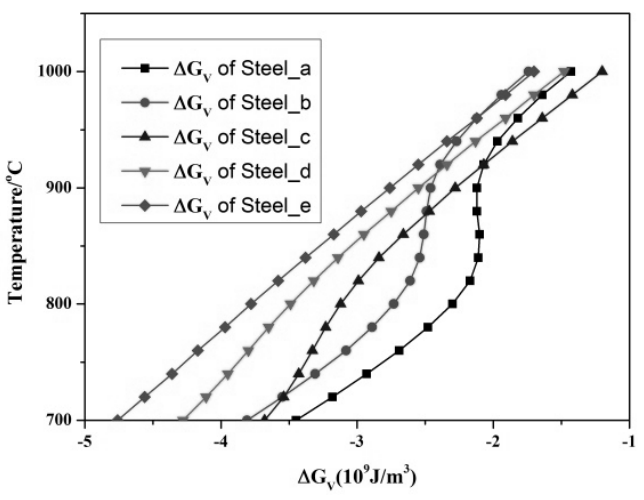

Fig. 6

Fig. 5. Effect of nitrogen content on PTT curves for the precipitation of vanadium carbonitride in austenite.

Fig. 6. Effect of nitrogen content on $\Delta G_{V}$ in austenite.

Figure 5 shows the effect of the nitrogen content on PTT curves for the precipitation of $\mathrm{V}(\mathrm{C}, \mathrm{N})$ in austenite for various compositions (Steel_a, Steel_b, Steel_c, Steel_d, and 


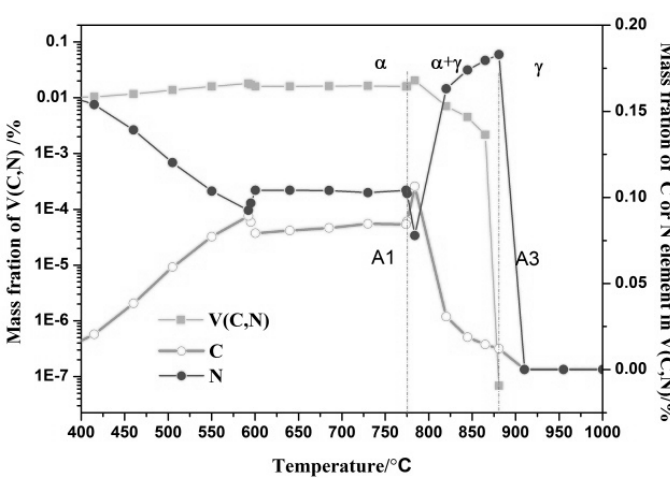

a

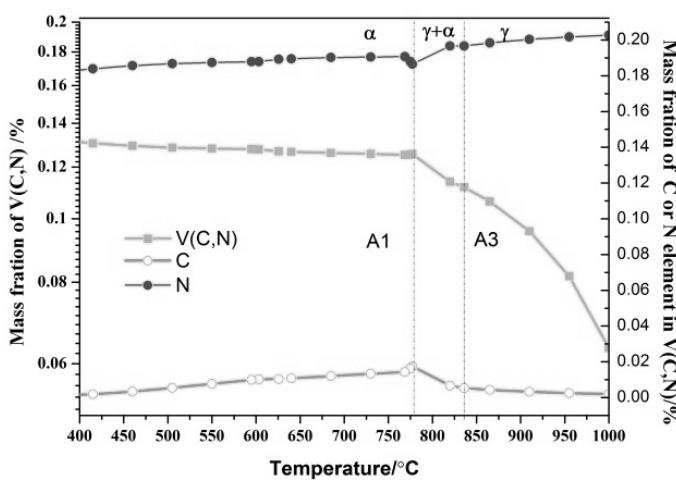

c

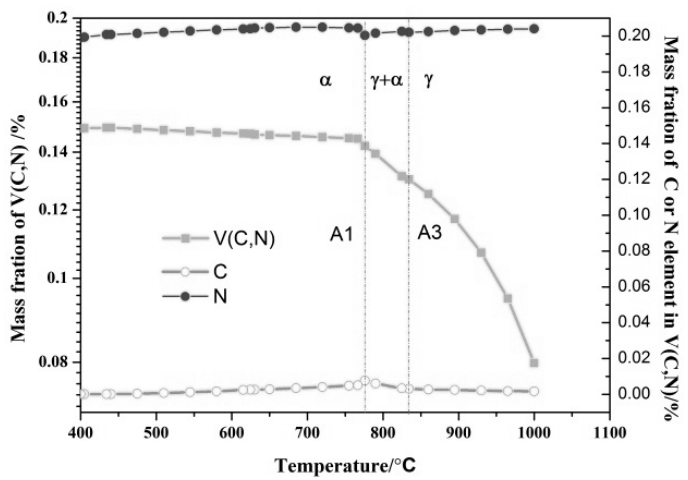

e

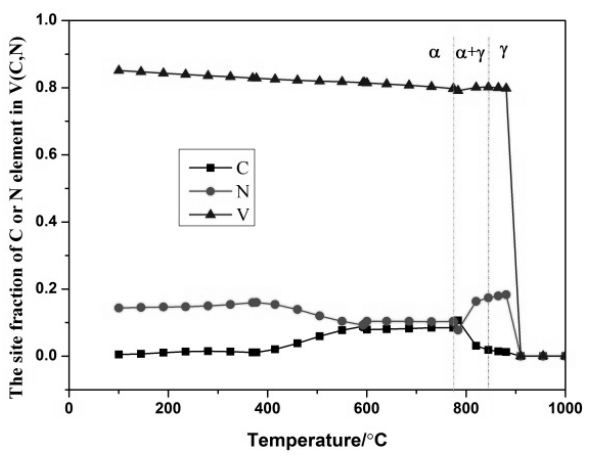

b

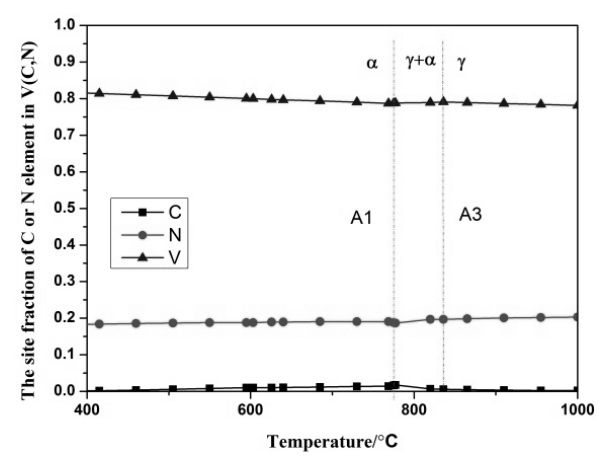

d

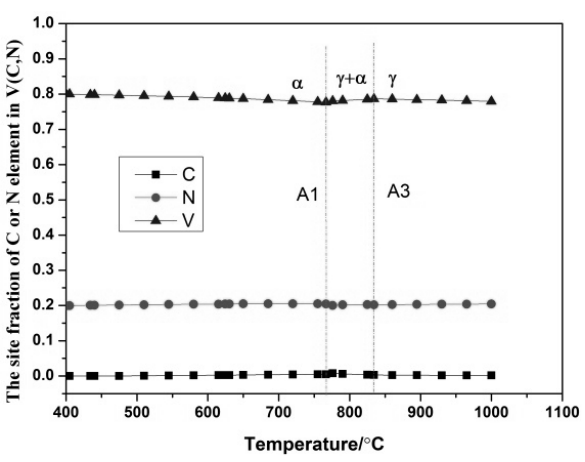

$\mathrm{f}$

Fig. 7. Calculated results for $\mathrm{V}(\mathrm{C}, \mathrm{N})$ in steels [(a) Steel_f, (c) Steel_d, and (e) Steel_e], and the site fraction of $\mathrm{C}$ or $\mathrm{N}$ for the precipitation of $\mathrm{V}(\mathrm{C}, \mathrm{N})$ in steels [(b) Steel_f, (d) Steel_d, and (f) Steel_e].

Steel e in Table 3). With an increase in the nitrogen content, the nose temperature of the PTT curve increases and shows a shift to the left. Above the temperature of the nose point, PTT curves change significantly, while below this temperature the PTT curves change very slowly. Hence, there is a maximum nucleation rate in a wide range of temperatures, and $\mathrm{V}(\mathrm{C}, \mathrm{N})$ effectively provides the precipitation strengthening in the actual rolling process. When the nitrogen content of the steel is reduced, the PTT curve shows a characteristic S-type shape, i.e., the fastest precipitation of the PTT curve has double peaks. Due to the lower nitrogen content, $\mathrm{V}(\mathrm{C}, \mathrm{N})$ cannot precipitate in austenite. 


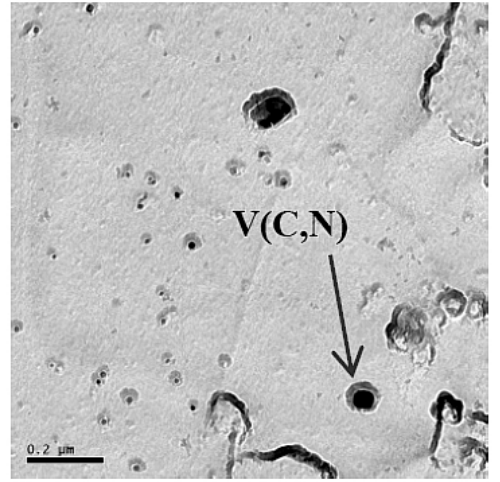

a

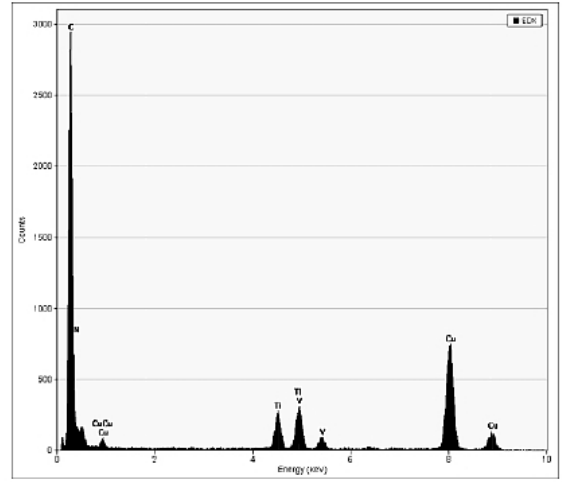

b

Fig. 8. V(C, N) precipitates (a) and energy spectrum of $\mathrm{V}(\mathrm{C}, \mathrm{N})$ precipitates of Steel_d (b) after air cooling to the room temperature by TEM and EDS.

Figure 6 shows the effect of nitrogen content on $\Delta G_{V}$ in austenite for different steels (Steel_a, Steel_b, Steel_c, Steel_d, and Steel_e in Table 3). The comparison of Figs. 4 and 6 in the temperature range of $750-850^{\circ} \mathrm{C}$ reveals that the change in the free energy of $\mathrm{V}(\mathrm{C}$, $\mathrm{N})$ precipitates is due to a rapid growth of $x$ value in $\mathrm{VC}_{x} \mathrm{~N}_{1-x}$ for low-nitrogen steels. The comparison of Figs. 4 and 6 shows that the apparent nonlinearity of phase change free energy for Steel_a and Steel_b causes the S-type characteristics of PTT curves. For threeor multi-component mutually soluble carbonitrides, there is a distinct difference in the solid solubility of vanadium nitride/carbide in the matrix. However, this difference is caused by changes in the chemical composition coefficient over a certain temperature range, which leads to the nonlinearity of the phase change free energy.

2.3. Thermodynamic Calculations for $V(C, N)$ Precipitation in $V-N$ Microalloyed High-Strength Weathering Steels. Phase equilibria were investigated by utilizing the CALPHAD approach. CALPHAD is based on the Gibbs energies of individual phases, which are expressed as a function of the composition and temperature. According to the general concentration of the new weathering steel in this study, multi-component phase diagrams of the $\mathrm{Fe}-4.0 \mathrm{Cr}-0.25 \mathrm{Ni}-0.4 \mathrm{Si}-0.7 \mathrm{Mn}-0.45 \mathrm{Cu}-0.03 \mathrm{Al}-0.015 \mathrm{Ti}-0.12 \mathrm{~V}-x \mathrm{C}-y \mathrm{~N}$ alloy system were constructed using the Thermo-Calc software jointly with the FEDAT database. The chemical compositions of these steels are listed in Table 3. As seen in Fig. $7 \mathrm{a}, \mathrm{c}$, and e, the temperatures of $A 3$ and $A 1$ for Steel_f, Steel_d, and Steel_e are $\sim 845$ and $776^{\circ} \mathrm{C}$, respectively; i.e., the two-phase region of austenite and ferrite is between 845 and $776^{\circ} \mathrm{C}$. Figure $7 \mathrm{a}$ shows that the precipitation phases of $\mathrm{V}(\mathrm{C}, \mathrm{N})$ for Steel_f cannot occur in the austenite zone. As seen in Fig. 7c and e, V(C, N) in Steel_d and Steel_e can precipitate as $\mathrm{VN}$ in the austenite region. As seen in Fig. $7 \mathrm{~b}$, $\mathrm{d}$, and $\mathrm{f}$, the site fraction of $\mathrm{N}$ in the precipitation of $\mathrm{V}(\mathrm{C}, \mathrm{N})$ for Steel_f is low; however, that for Steel_d and Steel_e is much higher. Therefore, steels with a high $\mathrm{N}$ content can precipitate as $\mathrm{VN}$ in the austenite matrix. The site fraction of $\mathrm{N}$ in the precipitation of $\mathrm{V}(\mathrm{C}, \mathrm{N})$ for steels of high $\mathrm{N}$ content is much higher.

2.4. The Observation of $\boldsymbol{V}(\boldsymbol{C}, \boldsymbol{N})$ Precipitates. Figure 8 shows $\mathrm{V}(\mathrm{C}, \mathrm{N})$ precipitates of Steel_d after air cooling to the room temperature. It is noteworthy that a few of $\mathrm{V}(\mathrm{C}, \mathrm{N})$ precipitates were dispersed in the matrix of Steel_d. Moreover, the structure of $\mathrm{V}(\mathrm{C}, \mathrm{N})$ precipitates is cubic. Figure $8 \mathrm{~b}$ depicts the energy spectrum of $\mathrm{V}(\mathrm{C}, \mathrm{N})$ precipitates for Steel_d, where some elements $(\mathrm{Cu}$ and $\mathrm{Al})$ are also shown in the energy spectrum.

Conclusions. The strain-induced precipitation kinetic model for cubic $\mathrm{V}(\mathrm{C}, \mathrm{N})$ precipitates in $\mathrm{V}-\mathrm{N}$ microalloyed high-strength weathering steels was constructed and 
validated. This model is based on the Johnson-Mehl-Avrami equation and uses the Adrian model to calculate the equilibrium phase information and the L-J model to calculate the free volume of precipitates. The calculated and experimental results exhibit a good fit.

The effect of nitrogen content on the PTT curves was studied; the nitrogen content has a strong effect on the precipitation behavior of $\mathrm{V}(\mathrm{C}, \mathrm{N})$ in austenite. With increased nitrogen content, the nose temperature of the PTT curve sharply grows, while the curves exhibit a shift to the left. After reducing the nitrogen content in steels, the PTT curves of $\mathrm{V}(\mathrm{C}, \mathrm{N})$ precipitates in austenite get characteristic S-type shape, due to the nonlinearity of free energy conversion process.

The Thermo-Calc software was employed jointly with the FEDAT database to calculate the phase equilibrium of $\mathrm{V}(\mathrm{C}, \mathrm{N})$ precipitates for new high-strength weathering steels. Steels with high $\mathrm{N}$ contents can precipitate in the austenite region in the form of VN. The site fraction of $\mathrm{N}$ in the precipitation of $\mathrm{V}(\mathrm{C}, \mathrm{N})$ in steels with high $\mathrm{N}$ contents is much higher than that in steels with low ones.

Acknowledgments. This work was financially supported by the project of green manufacturing system integration of MIIT China (2016-64).

1. Q. L. Yong, M. T. Ma, and B. R. Wu, Microalloyed Steel: Physical and Mechanical Metallurgy [in Chinese], China Machine Press, Beijing (1989).

2. H. Adrian, "Thermodynamic model for precipitation of carbonitrides in high strength low alloy steels containing up to three microalloying elements with or without additions of aluminium," Mater. Sci. Technol., 8, 406-420 (1992).

3. B. Dutta and C. M. Sellars, "Effect of composition and process variables on $\mathrm{Nb}(\mathrm{C}, \mathrm{N})$ precipitation in niobium microalloyed austenite," Mater. Sci. Technol., 3, 197-206 (1987).

4. W. J. Liu and J. J. Jonas, "Nucleation kinetics of Ti carbonitride in microalloyed austenite," Metall. Trans. A, 20, 689-697 (1989).

5. W. J. Liu, "A new theory and kinetic modeling of strain-induced precipitation of $\mathrm{Nb}(\mathrm{CN})$ in microalloyed austenite," Metall. Mater. Trans. A, 26, 1641-1657 (1995).

6. B. Dutta, E. J. Palmiere, and C.M. Sellars, "Modelling the kinetics of strain-induced precipitation in Nb microalloyed steels," Acta Mater., 49, 785-794 (2001).

7. P. Maugis and M. Gouné, "Kinetics of vanadium carbonitride precipitation in steel: A computer model," Acta Mater., 53, 3359-3367 (2005).

8. F. Fang and Q. L. Yong, "A model for precipitation kinetics in vanadium microalloyed steel," J. Iron Steel Res. Int., 17, 36-42 (2010).

9. Q. L. Yong, Secondary Phase in Steels [in Chinese], Metallurgical Industry Press, Beijing (2006).

10. M. Mukherjee, U. Prahl, and W. Bleck, "Modelling the strain-induced precipitation kinetics of vanadium carbonitride during hot working of precipitation-hardened ferritic-pearlitic steels," Acta Mater., 71, 234-254 (2014).

11. S. Zajac, "Precipitation of microalloy carbo-nitrides prior, during and after $\gamma / \alpha$ transformation," Mater. Sci. Forum, 500-501, 75-86 (2005).

12. C. Zener, "Theory of growth of spherical precipitates from solid solution," J. Appl. Phys., 20, 950-953 (1949).

13. W. A. Johnson and R. F. Mehl, "Reaction kinetics in processes of nucleation and growth," T. Am. I. Min. Met. Eng., 135, 416-458 (1939). 
14. M. Avrami, "Kinetics of phase change. I General theory," J. Chem. Phys., 7, 11031109 (1939).

15. M. Avrami, "Kinetics of phase change. II Transformation-time relations for random distribution of nuclei," J. Chem. Phys., 8, 212-224 (1940).

16. F. Fang and Q. L. Yong, "A model for precipitation kinetics in vanadium microalloyed steel," J. Iron Steel Res. Int., 43, 71-74 (2008).

Received 15. 09. 2017 